\title{
Fake as a Format of Modern Journalism: The Information Reliability Problem
}

\author{
Igor Nikolaevich Blokhin ${ }^{1 *}$ and Sergey Nikolaevich Ilchenko ${ }^{2}$ \\ 'Department of Theory of Journalism and Mass Communication, Saint Petersburg State \\ University, St. Petersburg, Russia \\ 2Department of TV and Radio Journalism, Saint Petersburg State University, St. Petersburg, \\ Russia; tv_and_radio@mail.ru
}

\begin{abstract}
The article is devoted to the study of such phenomenon in modern journalism as a fake. The study carries out an identification of patterns in the relationship between information flows and empirical reality in the context of showcivilization by analyzing the practice of Ukrainian conflictcoverage made by the Russian media. There were fixed fundamental differences in the interpretation of factual basis in the mass media. The authors define fake as the dominant format, which distorts the endeavor to create an objective reality in the information space. As a result of its widespread use in journalists' activity, there emerges a problem of reliability of the information obtained.
\end{abstract}

Keywords: Fact, Fake, Format, Information, Media, Show-Civilization

\section{Introduction}

Today, the term "fake" has become commonly used in media practice. In English, the word "fake" means "false, unreal", in common parlance it means "pseud". The term is mostly translated as a noun, and likewise, it carries a negative connotation because it means "fake, fabrication". Its most common sphere of usage is various network resources, ranging from the Internet portals to traditional media sites. Fake, being a phenomenon of the information sphere, is directly related to such global phenomenon as a show-civilization which simulates reality by creating a virtual reality in the electronic media, as well as in the network space. If a piece of news, information or an event is identified as a fake, it loses its credibility among the potential audience. L. M. Zemlyanova mentions this referring to the term "a fake report" as "a fabricated message with falsified or unreliable facts". The term comes from the word fake, meaning counterfeit, forgery, imposture. Fake news format is a pseudo-news format, with advertisements presented in the form of news blocks. In the emergence of such format analysts see symptom of developing media advertising advancement and displacement of public sphere by commercial news ${ }^{1}$.

In modern media practice, it is accepted to distinguish between the following types of fake:

- Counterfeit photos, which were processed in appropriate computer image correction programs aimed to increase their seeming authenticity.

- Video clips, assembled from the already used or the source material shot at the wrong time and in the wrong place, which they are designed to imitate.

- Basically, any counterfeit news, usually having non-authentic video illustration.

- Personal accounts in social media, created on behalf of others with the inevitable use of photographic images of a page "owner".

- Twitter fake accounts, which also have borrowed portraits.

All such kinds of permissive interpretation of information (both visual and verbal) indicate serious

${ }^{*}$ Author for correspondence 
discrepancies which can be found in the initial information functioning through various channels of mass communication.

\section{Literature Review}

In future we intend to identify such trends, seriously distorting the perception of worldview by the audience that could be more relevant to reality. Their connotation with the media issues is defined as one of the core features denoting such present day phenomenon of social development as show-civilization. Dynamic technological development oriented at information space significantly influences the situation with the information reliability. Digital revolution has made the proof of any fact very problematic," said D. Dragunsky. "This is due to the peculiarities of digital editing, and practically unlimited resources"2.

Such researchers as $\operatorname{in}^{3-8}$ wrote about the problem of reliability connected with the widespread introduction of the latest digital technologies. It's quite natural, that the problem of literal perception of information which comes into society through communication channels cannot be ignored in the description of modern state of civilization. The latter is defined differently by various researchers, but the scientific trend is obvious: This is a civilization of external perception or so-called show-civilization. We introduce this term in order to identify accurately the factors that influence the audience by distorting of incoming information. These provisions were developed by such scholars as in ${ }^{9-16}$.

The most critical problem of authenticity of incoming information is related to those political consequences which intentionally result into falsified messages and knowledge especially in communication channels such as television and network resources. This was covered in works of ${ }^{17-19}$. In a situation, when a political discourse starts to dominate in the practice of modern media, the problem of information source credibility is very important. These aspects, related to the problem under consideration, were analyzed by the following scholars ${ }^{20-22}$.

\section{Materials and Methods}

In order to understand the value of fake as a new format of journalistic practice, we resort to online sources and TV content analysis using the empirical material, which generates empirical area of our research. As a matter of fact for each authenticity proof obtained from the network resources it is possible to find the evidence capable to cast doubt among the audience. The usage of proof link strategy inevitably leads to counteractions based on the same proof link algorithm. Moreover, such a chain of arguments and counterarguments can be made endlessly taking into account the capabilities of existing information technology and the structure of network community. This forms a tempting context resulting in possible interpretations and their drastic consequences i.e., fraud. A Russian researcher impartially remarks that "the difference between a fake and a fact is gradually becoming blurred. In the digital sphere any fact can be proclaimed to be a fake and vice versa"2.

Analyzing fake as the newest format of processing primary information of all kinds and types, we need to address the twofold problem of research. On the one hand, it is obvious that there is a need to identify and primarily classify fake information distributed throughout the media of a specific kind and type. On the other hand, having identified the indicated problem of information reliability as the next phase of the study we need to approach the problem solution by formulating qualified mechanisms of protection against penetration of this phenomenon into everyday practice of not just media, but also of other channels of communication.

The famous slogan of modern professional journalists i.e., "fact is sacred, comment is free" is seriously verifying with respect to the functional acceptability in the modern show-civilization. The problem of unbiased broadcasting of information through the mass media is predetermined today by the number of factors which are outside the event component, based solely on the facts, which a journalist tries to describe in their article. In addition to the circumstances which the journalist encounters describing the events, he depends on the position of the manager or owner of that media in which he serves. He is naturally influenced by the editorial task, which specifies the time limits and the amount of future information presentation, as well as its format. The internal requirements which guide the behavior of a journalist in relation to those facts that he seeks to discover and publicize are on this list.

For example, some channels require the in-shot presence of a journalist during on-the-spot report (such practice is common, for example, in $\mathrm{CNN}$ ). In other mass media, there exists a special list of prohibited use of terms and concepts. 
Altogether, there are factors, guiding a journalistic idea when he works on the original material not in the direction of elaborating a balanced and impartial text, reports, but towards interpretation creativity, with the help of which the representative of a particular media forms not a real picture of the event, but its image, based on realized and not realized tasks. It is possible to claim even more categorically: In such a situation the journalist is inherently inclined to interpret the fact and events rather than reconstruct more or less related to reality ones. It is not a long way to resorting to techniques that are called "fake journalism" in professional slang. One of the most obvious and common examples, which will be analyzed below: Constant appeal to the network resources as a source of visual information.

Permanent use of the Internet as a source of primary materials, including that of visual nature, is not as innocent as it might seem at first glance. We have already repeatedly challenged the authenticity of journalistic work using similar techniques. The total impact of the listed circumstances, affecting the journalist, allows us to say that the latter being the subject of information activity turns out to be substantially dependent on what defines his attitude to events, information and facts. Among the obvious psychological mechanisms of such interpretation is the factor of speed delivery of obtained information to a potential user through one or another media channel. This factor is a derivative of sensationalism concept, which is deeply rooted in the practice of the majority of the world's media, including Russia. Only some media are trying to turn the situation, establishing professional standards of a different paradigm. For example, the management of the BBC Company did this in 2005 coming up with the following slogan for its employees - "accuracy is more important than the speed". Under this approach the journalists themselves experience difficulties to confront the acquiring of information and facts on a daily basis. As Pierre Bourdieu accurately remarks, "journalism is a rush, a constant flow of time"10.

Thus, a typical situation in journalists' practice (particularly those of media, which we refer to as audio and visual ones) looks like the following sequence of actions. Due to the impermanence and sometimes abruptness of events, a reporter does not have time to get the picture that captured an event or a discovered fact. Then there is a strong temptation to use alternative sources of visual information, which in the vast majority of cases is a social network of a different nature or status. Time pressure does not allow either to verify the authenticity of the borrowed pictures or its source and origin. A significant problem for reliable identification of the facts in such cases is filming of poor quality, which impairs perception of received shots by the audience. In this context, nobody and nothing can guarantee the authenticity of the received video and its relevance to the real cause of this or that event or a fixed fact. This, in fact, predetermines the use of fake as a format with the help of which information, data, news and facts obtained by journalist can be illustrated.

Show-civilization, as a dominant phenomenon in today's information space, specifies trends of mass perception of visual information, which is nowadays delivered to its potential consumers through various channels of communication. In this context, we should also bear in mind the dualistic nature of the Internet and its dual role in the system of mass communication at the beginning of the 21 st century.

On the one hand, the Internet is an unstructured virtual space for storage and emergence of information, striving for infinity and reproduction. On the other hand, it is one of the most popular channels for dissemination of information. Its circulation scheme - the Internetscreen media-the Internet, looks like a perfectly formed phenomenon in journalistic practice.

In current situation of information confrontation, which has unfolded around Ukrainian events, the ways of using videos from the web seem indicative in their ability to manipulate mass consciousness, evoking the desired moods. There is a well-known video footage which was made in February 2014 with the EuroMaidan supporters. People who are crawling under the shields can be seen on these video snapshots. Some of them fall on the ground, being affected by bullets fired from a sniper rifle. Oppositional (at that time) Ukrainian mass media and Western media interpreted this Internet video as the evidence of "the massacre" by the security forces, loyal to the incumbent at the time President Viktor Yanukovych.

Two weeks later it turned out that in a telephone conversation the Minister of Foreign Affairs Urmas Paettold EU High Representative for Foreign Affairs and Security Policy, Catherine Ashton that both the security officials and the supporters of EuroMaidan could have been shot dead by those snipers, who were hired by oppositionists for provocation purposes. The above mentioned telephone recording instantly appeared on different TV channels. It was interpreted as a possible evidence of deliberate snipers' shooting. 
Thus, the interpretation formation of the known and recorded facts happened in the electronic media on the basis of the same footage from the network. This created an opportunity for manipulation, in accordance with the political orientation of one or another media source.

For proper understanding of the whole range of problems associated with the use of a fake format in modern journalism, you must expand your understanding of the phenomenon of show civilization which is a key to ideology construction. Edgar Allan Poe, an American writer, created in his time a peculiar literary image of this concept in the short story "Berenice" (1835): "The realities of the world affected me as visions, and as visions only, while the wild ideas of the land of dreams became, in turn, - not the material of my every-day existence but in very deed that existence utterly and solely in itself." Developing such a precise verbal description, based on the creative intuition of the writer, we turn to the scientific statement of the identified phenomenon of contemporary reality. By the term show-civilization we understand the modern system of information relations in society, which are characterized by the conflicting relationship between the screen and empirical realities, due to the dominance of visual media distribution channels and interaction conflict between objective and subjective factors in the practice of the media.

The relationship issue between the imaginary reality, formed in the minds of the audience through the media, and empirical reality, theoretically emerged at that very moment when it became obvious that there was a gap between the technological and technical system of collecting, processing and delivery of information to the consumer and the journalists' physical abilities as professionals whose activity is focused on synonymic processes. Advanced development of technology has marked certain limitations in creative tools they possess. Journalists' dependence provokes them to form an inadequate picture of reality based on real facts. The final chain component of information flow is an audience which also turned out to be dependent from the fact how journalists will use uncovered technological opportunities of information interpretation. It explains the popularity of Daniel J. Boorstin's aphorism: "Nothing is really real unless it happens on television." It is the quintessence of our concept of show-civilization.

Historically, the starting point of its explicit presence and the mankind's perception of it date back to September 11, 2001 when the terrorist acts were committed live on television. It is their coverage in the world media testified to a fundamental transformation of not only the entire system of international relations on the planet, but also to a tragic borderline, which defined the role of media in such processes. In his book "Psychological Warfare" back in the mid-20th century American political scientist Paul Linebarger talked about the rapid changes taking place in the political reality and the inadequacy of mass consciousness to perceive them. In simple words, when the created media picture of the world did not give the audience to thoughtfully and carefully ponder on what happened, not to mention applying any analytical skills, "In the heat of the controversy," Paul Linebarger pointed out, "all of these people did not want to think about what events were evolving so rapidly that neither Communists nor their opponents are incapable of assessing their significance. Among these events are the invention of hydrogen bomb, the death of Stalin and the emergence of Israel on the world map. Well after the events occurred did many people understand what threat all these things posed"20.

Modern picture of the world is changing so rapidly in mass consciousness, that not only the media, but the audience do not have time to reflect on political, social and economic processes. They literally flock in pursuit of the events, when the speed of information dissemination in any form and in any capacity turns out to be of higher priority than the observance of journalistic ethical rules regarding the reliability of the evidence, facts and information. Politics has become a trends catalyst that in previous, stable period of life in Europe and in the world was not perceived as a total assault on the old principles of journalists' work and foundations strain of the entire media system.

Political radicalization of Ukrainian crisis, which resulted in many casualties, significantly contributed to this. Up to that moment, show-civilization acted extremely "selectively": Either in different variations of "color revolutions" around the perimeter of Russian borders, or in a single event like the excesses around the "bronze soldier" in Tallinn.

However, in the context of events coverage in Ukraine, starting from November 2013 by-products of showcivilization appeared in the activity of various media players, irrespective of their nationality, specialization and full status. We will analyze the most vivid examples of such occurrence in connection with the network technologies. 
The activity of news media portal North-West Lenizdat.ru will be the empirical basis for our analysis. It has existed since the year 2003 as a classic news site in a form of online-media. Official statistics of its popularity is 47900 visitors per month. As the source of information it is referred to by major media of St.Petersburg, Leningrad Region and the North-Western Region. Structurally and according to the type of information this data resource should be considered to be the regional media. But the dominant focus of this media employees are all aspects relating to the activity of the media. Lenizdat.ru therefore can be described as a site focused on professional audience both inside and outside the country.

On May 14, 2014 the management of the site has launched a new project entitled "Stop Lying." Its starters offered to tell on a daily basis about fraud information on "Ukrainian issue". At the start of the project a certain operational term - ukrofake was even put into circulation. It means incorrect information concerning different aspects of Ukrainian crisis, published by various media. However, examples from the Russian media only could be found in the first presentation of "Stop Lying". At the same time a double correction of this nomination was made. They added the adjective "Russian" to the term "ukrofake". In the meantime after several critical reviews made by the users of the resource concerning the unilateral nature of the project, the Lenizdat.ru management tried to mix the problem situation by publishing ukrofakes produced by Ukrainian and Western media. But the attempt was unsuccessful. A few non-Russian ukrofakes was published. The reasons for such imbalance are extremely important for understanding the format nature of fake, so we analyze them further.

While the article is being written, the project "Stop Lying" is on the point of stagnation. The latest selection of ukrofakes was published on the 4th of April 2015. It represents a digest of the most striking ukrofakes over the past period and contains 6 examples. Obviously, we can observe a certain exhaustion of ideas of searching for inaccurate information about the situation in Ukrainian media environment.

Overall, they published 75 facts in 22 editions within the analyzed project on the Internet site. Officially, they were called "ukrofakes". Sources statistics was as follows: 66 ukrofakes were found by the authors of the project in the Russian media of all kinds and types (television, radio, print media, news agencies, online resources). 4 ukrofakes were taken as examples of publications in Ukrainian media. 5 untrue facts described in the project have been identified in Russian and Ukrainian media.

As for the types of media that serve as a source for ukrofakes, the dominant trend is evident, indicating the virtual nature of the fakes that have a negatively creative impact on traditional media. Thus, the statistics of the revealed ukrofakes by the type of media in project "Stop Lying" for almost a year of the project existence was as follows: 39 examples were found on the Internet and various information portals. 20 ukrofakes were found by the authors of the project in the publications of print media. 13 examples were discovered on television, and only 3 ukrofakes were sounded on the radio. It is clear that in some cases unproven facts were disseminated through various channels of mass communication, but we think it possible to keep statistics, taking into account the primary media that put this or that fake into informational space.

Note that even in those cases when ukrofake was marked by the authors of the project in traditional media, the further investigation of a specific case led to the primary source of unverified information, which most often turned out to be one or another network resource. This is, by the by, one of possible reasons, in our opinion, why the project had a high attrition rate and why Lenizdat. ru users responded reluctantly to it. "Stop Lying" released only 22 issues and only ones - in issue\# 16 of October 11, 2014 year - just over ten responses from readers were recorded (12).

We can assume that such audience inactivity was due to several factors. First of all, it was an excessive information redundancy of all media that covered the situation in Ukraine. We have identified that the negative part was played by the disparities in use of ukrofake sources that could make an impression on some audience concerning the biased attitude of the authors of "Stop Lying" project towards the Rusian media environment. However, the project incurred the most significant costs in public image when it tried to ignore the ethical dimension in the journalists' work, which was analyzed by Lenizdat.ru staff.

This trend is particularly evident in the publication of the latest ukrofake in "Stop Lying" issue dated July 4, 2014 (No. 7). It deals with the credibility of the official version of Anatoly Klyan's death, the First Channel cameraman. The essence of "Stop Lying" authors' claims comes down to the fact that he allegedly died from a heart attack, but not from a bullet. We do not dispute the existence of 
possibly different versions with regard to this tragic fact. But we think it is ethically impossible to discuss human death as a probable media fake. However, as we will see later, this trend of "fake creation" in the events coverage becomes dominant in Ukraine.

In our opinion "Stop Lying" also suffered a reputational loss due to fact the authors resort to the same network resources (even personal accounts on Twitter, as well as the recordings from YouTube) as counter-arguments and evidences of unreliable journalistic fake which predominantly have the network origin. Moreover, the majority of these resources were organized and registered in Ukraine just in the midst of Euro Maidan events. Among them are StopFake.org and Fake.Control.

\section{Results}

This method of determining authenticity of certain facts already circulating in the media sphere we do not consider theoretically being the correct one, for the users of such networkresourcesarenotimmune from such manipulation on the part of their creators. The phenomenon of trolling, widely spread in network circulation of information, is the best argument in favor of a more critical attitude towards the Internet as a source of reliable information. Moreover, such striving for objectivity and impartiality of media and journalists activity becomes obsolete due to the emergence of present information confrontation of various national media systems, which have adopted paradigms of action completely opposite to each other in meaning and content. Such concepts like "agitation" and "propaganda" have come back into use not only of media researchers, but also of practitioners. "Beliefs conflicts, which take place in the media -NiklasLuhmann pointed out in his article "The reality of the media" - are often carried out in a variety of actions with casual attributions and thus take the form of a compact, indecomposable bonds of facts"'.

The international community, especially the part of it that is involved or engaged in the situation in Ukraine, faces the information space, which has become a space of psychological warfare, which Linebagrer described in his study in the mid-twentieth century. American theorist of psychological warfare never indulged in illusions about the concept of information reliability in the media. He rightfully pointed out that in the context of war other mechanisms of information broadcast work (or should work) towards the audience. In simple words, he stated that the rules of propaganda are applied in such excess condition. Almost all effective propaganda - no matter what it is - is true. It merely uses the truth selectively" 20 .

In such informational situation the emergence of fake as an instrument of journalism is not surprising, since there is a permanent struggle, not only for the speed of information delivery, but also for the speed of introduction by explicit or implicit manipulation of the version of events or reality, that is the most beneficial and appropriate for the particular opposing party in the media. Ukrainian conflict, to our regret, gives many examples of the emergence of such fakes, which are appropriate to be called "macro fakes". The most obvious example is the story of tragedy versification connected with the crash of Malaysian "Boeing" in the sky over Ukraine on 17 July 2014. In this article we do not intend to assess the reliability of different versions of the aircraft crash. It is important to note the speed of their emergence in the information space that can serve as an indirect proof of their fake nature.

If you recall the "ABC media" by Norbert Bolz, his statement that the modern media "are always fighting for the scarce resource which is attention"3 seems more than relevant and fair in such context. The fight for the audience's attention is the fight for ratings. Any methods are appropriate here ranging from fakes to prank movement. The latter is gaining strength and is becoming a notable segment in the field of information confrontation over Ukrainian events.

The word "prank" means frolic, joke, drollery, and artifice. However, the term is actually used in relation to telephone calls. In modern media practice the prank is mostly inherent in the radio and television. It is used as a method of misleading the audience as well as an individual who becomes the subject of public jokes. We can say that today prank is a variant of fake in audio and visual media. They are united by a fundamentally manipulative nature of journalistic activities aimed at the creation of authenticity illusion both in audience's and counterparty's minds during a phone call and after the publication of a fake in print or on the network resource.

One of the most notorious examples of prank journalism is the story which happened on television program "Shuster.Live" which is broadcast on Ukrainian television channel "112". On May 29, 2015 there was a live call from a man who introduced himself as a Russian 
officer. Allegedly, he had experience in the conflict on the side of Donbassmilitants. Within twenty minutes the show presenter Savik Shuster and the guests in the studio asked their questions, mainly oriented towards the support of their version concerning participation of the Russian army in the conflict in the South East. The caller replied in detail, without hiding any data down to the titles and the names of their commanders. The prank end was of phantasmagorical when the caller unexpectedly for the Ukrainian audience mentioned his real name and explained that all his stories were absolutely fantastic ones. They have nothing to do with the reality.

The caller was a well-known pranker, called Lexus, whose real name is Alexey Stolyarov. His prank work is well known in Ukrainian media, since the case with Savik Shuster program was far from being the first one. Moreover, the very style of communication between the pranker and Ukrainian journalists at the first stage of making contacts was a clear indication of possible complications due to the unreliability of his possible references. During the week the authors of the program could have verified the authenticity of the obtained information and confirmed the existence of a real person who introduced himself using a false name and surname. However, the stereotype of professional journalistic consciousness, based on the fake format, turned out to be an embarrassment on the air.

\section{Conclusions}

Fake as a format of information activity in modern conditions of intensified conflict in the media has become a reality of journalistic practice. Professional journalists' society having become unwillingly the parties and the witnesses of an absolutely new geo informational situation tried to develop their own protective mechanisms in the media confrontation during 2014-2015, as indicated by the examples we provide. However, the range of problems covered in this article requires further theoretical development.

Real conclusions about the options for a possible opposition to "the emergence of fake" in media practice are mainly related to the functioning of the mass media itself, principles of its editorial policies, information standards which this or that media source adheres to. In this aspect, you can recall the experience of "Washington
Post" management, which strongly demanded from the journalists Carl Bernstein and Bob Woodward to confirm the information obtained from a second independent source during the Watergate scandal investigation.

The authenticity of facts, information and opinions received by the reporter, should be the desirable goal of his professional activity. Otherwise, we will have to agree with NiklasLuman: "It seems that the mass media protect and at the same time undermine the faith in their own credibility ${ }^{6}$.

\section{References}

1. Zemlianova LM. Kommunikativistika i sredstvainformatsii. Anglo-russkiytolkoviyslovarkontseptsiyiterminov. [Communicative approach and information resources. English-Russian Glossary of Concepts and Terms]. Moscow: MGU Press; 2004. [in Russian].

2. Dragunsky DV. Otnimatipodglyadivat. [Take away and peep]. Moscow: ACT; 2014. [in Russian].

3. Bolz N. Azbukamedia. [Das ABC der Meiden]. Moscow: Europa; 2011.[in Russian]

4. Giddens A. Posledstviyamoderna. [The consequences of modernity]. Moscow: Praksis; 2011. [in Russian].

5. Debray R. Vvedeniye v mediologiyu [Introduction a la mediologie]. Moscow: Praksis; 2009. [in Russian]

6. Luhman N. Real'nost' SMI. [Die Realitat der Massenmedien]. Moscow: Praksis; 2005. [in Russian].

7. Morozov E. Setevoyobman. Temnayastorona internet-svobody. [The net delusion: The dark side of the internet freedom]. Moscow: ACT; 2014. [in Russian].

8. Ulanova MA. Internet zhurnalistika. [Internet-journalism]. Moscow: Aspekt Press; 2014. [in Russian]

9. Bensaid D. Spektakl' kakvysshayastadiyatovarnogofetishizma [Le Spectacle, StadeUltime Du Fetichisme De La Marchandise]. Moscow: IOI; 2012. [in Russian].

10. Bourdieu P. Sur la Television et le Journalisme. Moscow: Fond nauchnikhissledovaniy "Pragmatikakultury", Instituteksperimentalnoysotsiologii; 2002. [in Russian].

11. Volkova I. Homo ludens v epoxy ekrannykhcommunicatsiy. [Homo ludens in screen communication epoch]. Moscow: RUDN; 2014. [in Russian].

12. Debord G. Obshchestvospektaklya. [La Societe du Spectacle]. Moscow: Radek; 2000. [in Russian].

13. Zizek S. Chumafantaziy. [The plague of fantasies]. Kharkov: Gumanitarniy Centr; 2014. [in Russian].

14. NovikovaAA. Televizionnayarealnost: ekrannayainterpretatsiadeystvitelnosty. [TV reality: Screen interpretation of reality]. Moscow: Izdatelskiy Dom VissheyShkoly; 2013. [in Russian].

15. Postman N. Amusing Ourselves to Death. New York; 1985.

16. Shkuratov VA. Iskusstvoekonomnoysmerty.Sotvorenievideomira. [The art of economical death. The creation of the video world]. Rostov-na-Dony: Narradigma; 2006. [in Russian]. 
17. Ghonim W. Revolyutsiya 2.0 [Revolution 2.0]. St.Petersburg: Lenizdat, Komanda A; 2012. [in Russian].

18. Mickiewicz E. Televideniye, Vlast' iObshchestvo. [Television, power and society]. Moscow: Aspekt Press; 2013. [in Russian].

19. Matheson D. Media diskurs: Analiziruyateksty SMI. [Media discourses: Analyzing media texts]. Kharkov: GumanitarniyCentr; 2013. [in Russian].
20. Linebarger P. Psikhologicheskayavoyna. [Psychological Warfare]. Moscow: Tsentrpoligraf; 2013. [in Russian].

21. Foley M. Vekabsurda. Pochemu v sovremennoyzhiznitrudnobyt' schastlivym. [The age of absurdity. Why modern life makes it hard to be happy]. Moscow: Yunaited Press; 2011. [in Russian].

22. Ekman P. Psikhologiyalzhi. [Telling lies]. Moscow: Piter; 2009. [in Russian]. 